\title{
Integration of Historic Building Information Modeling (HBIM) and 3D GIS for Recording and Managing Cultural Heritage Sites
}

Conor Dore

Technological University Dublin, conor.dore@mydit.ie

Maurice Murphy

Technological University of Dublin, maurice.murphy@tudublin.ie

Follow this and additional works at: https://arrow.tudublin.ie/beschreccon

Part of the Historic Preservation and Conservation Commons

\section{Recommended Citation}

Dore, C., Murphy, M., (2012), Integration of Historic Building Information Modeling and 3D GIS for Recording and Managing Cultural Heritage Sites, 18th International Conference on Virtual Systems and Multimedia: "Virtual Systems in the Information Society", 2-5 September, 2012, Milan, Italy, pp. 369-376. doi:10.21427/e7sy-rt81

This Conference Paper is brought to you for free and open access by the School of Surveying and Construction Management at ARROW@TU Dublin. It has been accepted for inclusion in Conference papers by an authorized administrator of ARROW@TU Dublin. For more information, please contact arrow.admin@tudublin.ie, aisling.coyne@tudublin.ie, gerard.connolly@tudublin.ie. 


\title{
Integration of Historic Building Information Modeling (HBIM) and 3D GIS for Recording and Managing Cultural Heritage Sites
}

\author{
C. Dore, M. Murphy \\ School of Construction \\ Dublin Institute of Technology \\ Bolton Street Campus, Dublin 1, Ireland \\ conor.dore@mydit.ie
}

\begin{abstract}
This paper outlines a two stage approach for digitally recording cultural heritage sites. This approach involves a 3D modeling stage and the integration of the 3D model into a 3D GIS for further management and analysis. The modeling stage is carried out using a new concept; Historic Building Information Modeling (HBIM) which has been developed at the Dublin Institute of Technology [12]. Historic Building Information Modeling is a system for modeling historic structures from laser scan and photogrammetric data using Building Information Modeling (BIM) software. The HBIM process involves a reverse engineering solution whereby parametric objects representing architectural elements are mapped onto laser scan or photogrammetric survey data. A library of parametric architectural objects has been designed from historic manuscripts and architectural pattern books. These parametric objects were built using an embedded scripting language within the BIM software called Geometric Descriptive Language (GDL). These objects are combined and mapped onto the survey data to build the entire model. After the 3D model has been created the next stage involves integrating the 3D model into a 3D GIS for further analysis. The international framework for 3D city modeling, CityGML has been adopted for this purpose. CityGML provides an interoperable framework for modeling 3D geometries, semantics, topology and appearance properties [13]. The aim of this research is to bridge the gap between parametric CAD modeling and 3D GIS while using benefits from both systems to help document and analyze cultural heritage sites.
\end{abstract}

Keywords - Laser Scanning; Parametric Modeling; BIM; Semantic Modeling; 3D GIS; CityGML, Cultural Heritage

\section{INTRODUCTION}

The generation of 3D cultural heritage models has become a topic of great interest in recent years. One reason for this is the more widespread use of laser scanning and photogrammetry for recording cultural heritage sites. These technologies have made it possible to efficiently and accurately record complex structures remotely that would not have been possible with previous survey methods. In addition to these developments, digital information systems are evolving for the presentation, analysis and archival of heritage documentation. These new digital information systems allow for the production of multi-purpose ' $\mathrm{nD}$ ' models that can be used for more than just visualization.

This paper presents a design framework for the integration of two new developments in this area, Historic Building Information Modeling (HBIM) and CityGML. HBIM provides a solution for parametric modeling of historic buildings/objects from laser scan or photogrammetric survey data. HBIM includes a plug in library of architectural objects for Building Information Modeling software platforms and a system for plotting these objects to laser scan or photogrammetric survey data.

After a HBIM model has been created the next stage involves the integration of the 3D model into a 3D GIS for further management and analysis. CityGML, an Open Geospatial Consortium (OGC) standard 3D data format has been adopted for this purpose. CityGML has a detailed semantic framework for city objects and enables further information to be stored as attributes or external references. The aim of this paper is to build on the new concept of Historic Building Information Modeling (HBIM) and to investigate the integration of HBIM into a 3D GIS environment using the CityGML framework for the purpose of cultural heritage modeling.

Section II of this paper contains a literature review for the main topics involved with this research. Section III contains a methodology for the proposed workflow and includes a case study which demonstrates the entire process from laser scan/image survey to HBIM, to $3 \mathrm{D}$ GIS as seen in Fig. 1 below. Section IV describes the next stages of work to be carried out in this area and finally section $\mathrm{V}$ contains the conclusions to date.

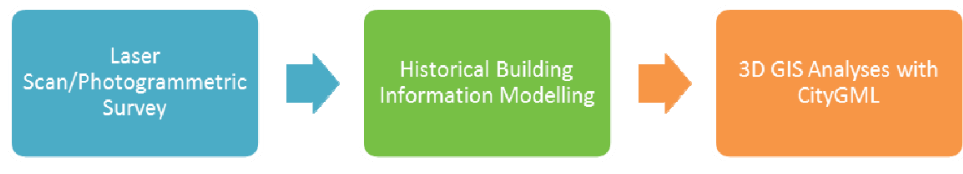

Figure 1. Workflow 


\section{LITERATURE REVIEW}

\section{A. Building Information Modeling}

Building Information Modeling (BIM) is a recent advancement in computer aided design (CAD) systems. BIM differs from traditional CAD systems because it is based on information enhanced parametric building elements, which are combined to create whole buildings within a virtual environment. In addition to $3 \mathrm{D}$ visualization and animations, BIM can automate the production of digital documentation (3D, orthographic projections cut sections, details) and design schedules for economic, structural, environmental and energy functions. The parametric objects (such as windows, doors, walls, roofs etc.) store data relating to the object and its relationship to the whole building and are not defined singularly but as systems using interaction with other objects.

\section{B. Historic Building Information Modelling}

Historic Building Information Modeling (HBIM) as plug-in for BIM is a novel prototype library of parametric objects built from historic data and a system for mapping the parametric objects onto a point cloud and image survey data. The HBIM process begins with remote collection of survey data using terrestrial laser scanning or digital photo modeling. A library of parametric objects were designed and constructed which are based on the manuscripts ranging from Vitruvius to 18th century architectural pattern books. In building parametric objects, the problem of file format and exchange of data has been overcome by using geometric descriptive language (GDL). The scripting in GDL allows for sharing and editing of the parametric objects at different levels. The plotting of parametric objects onto the laser scan or other survey data as building components to create or form the entire building is the final stage in the reverse engineering process.

\section{1) Related Research}

With the exception of [7], very little work has been done in relation to modeling historic buildings and also generating BIM models from laser scan survey data. Their work concentrated on the problems associated with combining laser scanning and BIM and plotting generic library objects onto the scan in a BIM environment. Within the research areas of both procedural and parametric modeling the use of architectural knowledge to inform the creation of models has now developed into a common part of the design approach. Existing research [5], [3] in the area of parametric modeling of architectural heritage has initiated a new direction by examining how architectural historic rules can be exploited to build computer models of structures and their elements. While these works inform the HBIM approach they differ in their way of approach to the analysis of historic data and parametric design.

\section{C. $2 D \& 3 D$ Geographic Information Systems}

A Geographic Information System (GIS) is used for storing, visualizing and analyzing geographic data. Spatial features are stored as geometry and referenced with map projections and coordinates. Attributes stored in tables are then associated with spatial features to allow for spatial analysis of data. GIS has traditionally been used with 2D mapping to analyze data over large areas. However, as a result of technological advancements, the principles of 2D GIS are now being applied to 3D spatial data to enable more complex analyses, visualization and documentation. This enables complex analysis to be carried out for many applications such as $3 \mathrm{D}$ cadaster, planning, disaster management, noise mapping and also cultural heritage.

\section{CityGML}

CityGML is an international standard data format for representing 3D urban objects. It facilitates the exchange of 3D data and supports the "sustainability and interoperability of 3D objects" [14]. CityGML is an Extensible Markup Language (XML) format which is an application of the Geographic Markup Language 3 (GML3). Unlike many other 3D data formats, CityGML can store more than just 3D geometries. CityGML describes objects in relation to their geometrical, topological, semantical and appearance properties [8]. This allows for many more applications of 3D models. In the past $3 \mathrm{D}$ models have been used primarily for visualization purposes. With the addition of topology and semantic information complex analysis and 3D spatial queries can be carried out in a GIS environment.

CityGML has a detailed framework defined for modeling the most important city elements. This framework includes core modules for buildings, relief, vegetation, transportation, water bodies, city furniture and land use. Each module has a framework defining semantic classes, attributes and relationships (topology) that are used to model city objects.

By using this CityGML framework for modeling city objects, it ensures the interoperability of the model and adds many capabilities to the model. These capabilities include:

- The ability to semantically classify and divide a model into its sub elements.

- The ability to define attributes and external references within the file which are associated with semantic elements in the model.

- Capabilities for integration of CityGML files into a database for efficient management and analysis.

- Web capabilities for sharing data as format is structured and coded in xml.

- Great geo-referencing capabilities as mapping projections and coordinate reference systems can be defined at the start of the CityGML file. All geometric objects are stored using coordinates relative to the defined coordinate reference system.

- Representation at five different levels of detail depending on the application.

- Capabilities for complex analysis of geometry, semantic classes, attributes, external references and topologies in a GIS platform.

\section{1) Applications of CityGML}

Current applications of CityGML are focused around city modeling for planning, disaster management [8], 3D cadaster [10] and other applications. Although CityGML was designed for city modeling, because of its capabilities and interoperable design it would also be suitable for 3D heritage modeling. With the exception of [4] and [6] very little research has been carried out applying CityGML for cultural heritage applications. Research in [4] focused on future perspectives for archaeological documentation where CityGML was assessed for the management of spatial and geographic documents. In 
this research modifications were made to the CityGML profile for archaeological purposes. This included an extension to the schema topology_xsd to represent stratigraphical units.

In [6] CityGML is adopted as an approach to semantic modeling of cultural heritage objects. An extension was also developed for the CityGML framework by these authors to accommodate for intervention and monitoring of cultural heritage sites. Although both of these contributions to semantic cultural heritage modeling with CityGML are very beneficial they have not shown the full capabilities of CityGML for heritage modeling that were mentioned previously. Both research works have shown that an extension to the existing CityGML framework is needed for cultural heritage modeling to define additional semantic classes and attributes that would be unique for cultural heritage applications. In this paper a more detailed extension is proposed for accurate semantic modeling of architectural detail in the CityGML framework. To date such an extension has not been developed and would be very beneficial for extending CityGML for the application of heritage modeling.

\section{E. Combining BIM and GIS}

There are many advantages of combining CAD products and GIS. CAD is mostly used for engineering applications and the products are generally detailed and accurate drawings or models of small objects or sites. GIS on the other hand is seen as cartographic tool for mapping and analyzing data over larger areas. Spatial data for GIS would not be considered as accurate or detailed as spatial data created in CAD systems. By combing both systems the capabilities and advantages of both CAD and GIS can be utilized. This would result in accurate and detailed CAD products used in a GIS platform that could be linked to additional data to perform complex analysis and spatial queries.

For the application of cultural heritage, detailed and accurate 3D models are required. In order to develop a 3D GIS for this purpose it is necessary to integrate CAD and GIS as detailed 3D models cannot be created in most GIS platforms. One of the main problems with this is interoperability problems with CAD and GIS datasets.

Unlike standard CAD products, BIM products which are based on the international standard Industry Foundation Class (IFC), has great capabilities for integration into a GIS platform. This is because IFC is an interoperable standard format that is object orientated and semantically classified. This is crucial for a GIS and CityGML as the model contains more than just geometry and it enables the IFC semantic classes to be converted into suitable GIS/CityGML classes with attributes and further information.

Existing work in this area [1] has shown the capabilities of integrating BIM and GIS for planning, 3D cadaster, environmental simulations and disaster management. In this research CityGML was also adopted and an extension to CityGML was created for integrating BIM models into CityGML. BIM and IFC concentrate on modeling buildings and as a result have very detailed semantics for buildings. CityGML on the other hand is more focused on city modeling so it does not have the same level of semantics for buildings. For this reason authors of [1] developed a BIM extension to CityGML which added new semantic classes for buildings. This research has shown it is possible to integrate BIM models into CityGML and extend the CityGML model for a specific application.

\section{METHODOLOGY}

In this section a methodology is presented for the initial stages carried out in further developing the HBIM process and the integration of HBIM into CityGML for heritage modeling. A case study is also presented to show the entire process applied to a heritage site located in Dublin, Ireland. This research is still in progress so only the initial results are presented in this paper. The next stages of research to be carried out are described in section IV.

\section{A. Historic Building Information Modelling}

A number of developments have been made to the existing HBIM process developed [12] which was described in section II. These developments are to assist the integration of HBIM to CityGML and also to increase the level of automation in the process. These developments are described in the following sections.

\section{1) Integrating Survey Data}

The first development is to improve the methods for integrating data from a laser scan/photogrammetric survey. BIM software is normally used to model new proposed buildings as opposed to existing buildings. For this reason precise geo-referencing of objects is not crucial in most BIM models. Products from the laser scan/photogrammetric survey that are imported into the HBIM environment include orthographic imagery, segmented point clouds and cut sections. Previously these products were imported and aligned together using a 'best fit' alignment method and did not maintain their true geo-referenced position. Datasets were placed in a new arbitrary coordinate reference system within the BIM software. This process has been changed so that all datasets are now capable of being imported using their true coordinates into a HBIM environment. Firstly this ensures there is no loss in accuracy when joining multiple datasets as products are positioned precisely with their true coordinates. This also enables geo-referencing to be later utilized in a 3D GIS which is a key part of CityGML and the GIS paradigm.

Because BIM is not designed for importing laser scan or survey data, a number of steps were developed to import 3D survey data. An orthographic image representing a building façade or plan is an important tool for HBIM modeling. This was previously imported in $2 \mathrm{D}$ and aligned to other datasets in elevation. This can results in inaccuracies and a build-up of errors when aligning multiple orthographic images. A new method was developed to accurately integrate $3 \mathrm{D}$ ortho images in their true geo-referenced position. This involved using the embedded scripting language within the BIM software to create a textured $3 \mathrm{D}$ plane that can be positioned based on the true coordinates of the image. Using correctly positioned 3D orthographic images ensures objects mapped to multiple images will be in their correct relative and absolute positions.

Other survey products such as segmented point clouds can be imported and used to generate a ground terrain model. This can be carried out using a mesh command within the embedded scripting language. This enables ground points from the survey data to be imported in their true position from their 3D coordinates and a mesh surface generated. As seen in Fig. 2 below all survey datasets are easily and accurately integrated when referenced with their true coordinates. 


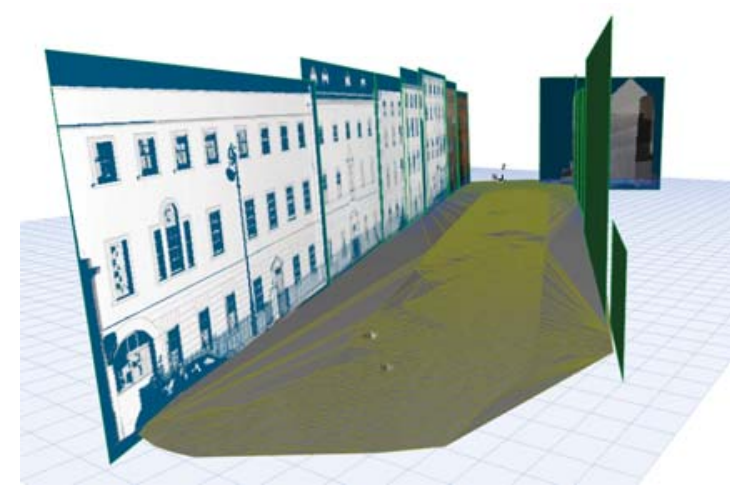

Figure 2. Accurate Integration of Scan Data into HBIM

\section{2) Parametric Libraries}

A library of parametric architectural objects has been created which are based on the manuscripts ranging from Vitruvius to 18th century architectural pattern books. Classical architectural buildings are made up of decoration in the form of moldings (Fig. 3) which are combined with cylindrical and planer objects and are brought together, based on a series of rules in relation to space, geometry and aesthetics to create a whole structure. By starting with the design of parametric moldings as the smallest building block, followed by the parametric design of elements such as columns, pediments, walls, windows, roofs etc. a design framework based on parametric design and shape rules is presented. The library objects were created using an embedded scripting language within the BIM software called Geometric Descriptive Language (GDL). GDL provides access to modeling of objects through a BASIC like language; these objects are specifically constructed for one or many uses and carry the required parametric information for the object's function. Shapes are scripted, based on primitives that represent the simplest solid objects; these are the building blocks of GDL and culminate to create the more complex parts.
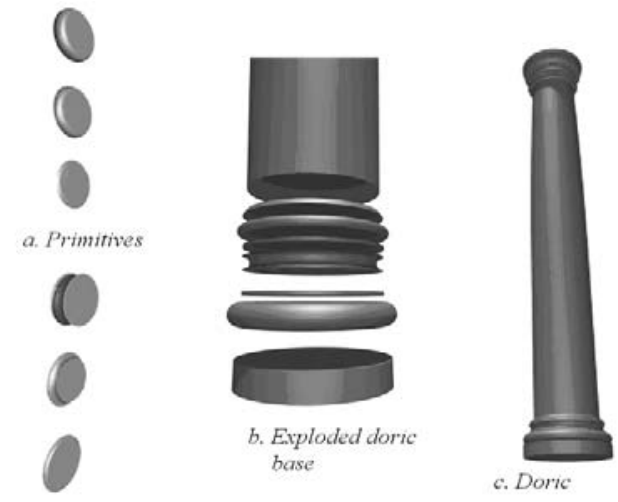

Figure 3. Combined Primitives for Doric Column

The previous HBIM libraries (Murphy et al. 2009) focused on objects for historical buildings. As stated by Boehler and Heinz (1999), it is equally important to record topography and other objects surrounding a heritage object/building to provide context. For this reason the HBIM libraries have been extended to include further elements that may surround historic buildings. New parametric objects and new procedures have been developed for modeling terrain, roads, footpaths, walls, railings, steps and street furniture as seen in Fig. 4. A framework for these features is also well defined in CityGML so this geometric and semantic information is very valuable for further analysis in a 3D GIS.

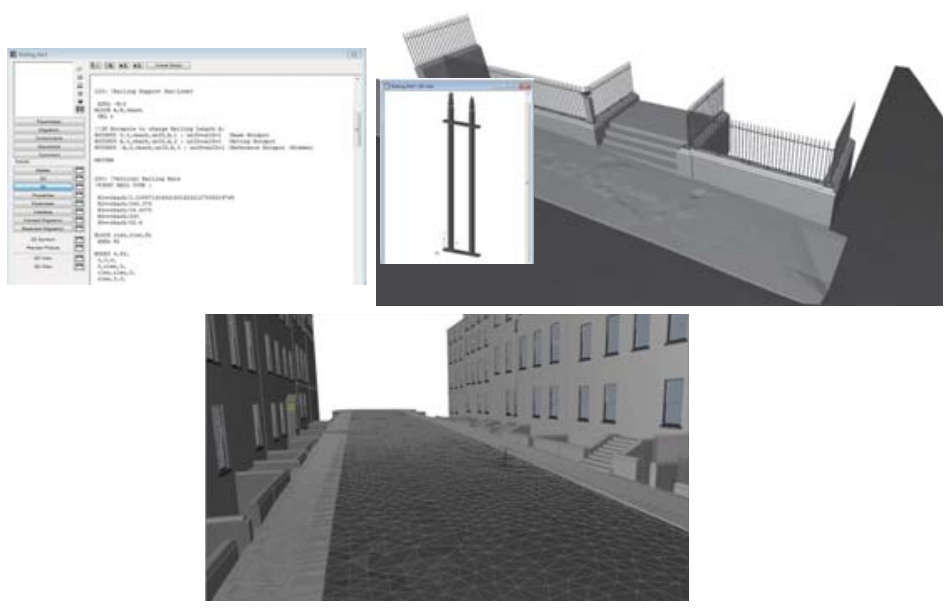

Figure 4. Extending HBIM with new library objects for elements surrounding buildings.

\section{3) Plotting Parametric Objects onto Laser Scan/Image} Data

Mapping objects directly onto a point cloud is not practical as the data size of the point cloud can be very large which will slow down data processing. In addition accuracy is affected by mapping in 3D space, as it is difficult to locate an object's exact position within a 3D point cloud. The proposed solution is to map the objects in 2D onto segmented point clouds and orthographic images in elevation, plan and section. Before placing a library object in HBIM the default parameters of the object can be edited, changing the object's shape, size or other properties to correspond with the survey data. When library objects are brought into HBIM they are first positioned in plan using ortho imagery or cut sections through the point cloud. The height of the object is specified by a parameter for its formation level. Objects are then more precisely positioned in front and side elevation from further ortho imagery and cut sections.

The positioning and plotting of objects can be further automated by making improvements to the parametric design. Using the embedded scripting language an entire external wall or building façade can be treated as a single library object. The positioning of window openings can be set up from rules of proportion outlined in architectural pattern books. A typical panel of a Georgian façade is modeled on the left side of Fig. 5. A series of openings are established using a GDL script for cutting the openings in the wall panel. The modular wall panel contains a series of openings laid out in the typical classical proportion. There are two large openings represented by two circles, one medium opening represented by intersecting circles and one small opening represented by one circle. The width of the window A (the circle's diameter) is a common factor in setting up the proportions, and is used to establish the position of the openings in the wall as detailed in the section of GDL script on the right of Fig. 5.

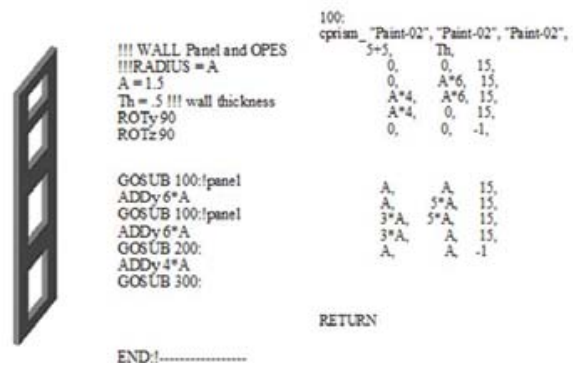

Figure 5. Wall Façade as a GDL Object 
Using GDL it is possible to add further parameters (by means of editable 3D hotspots) that can be used to interactively edit the position of window openings that don't match to survey data within HBIM either in 2D or in $3 \mathrm{D}$ (Fig. 6). This is necessary as all buildings won't conform exactly to the rules of proportion. However by first constructing an 'ideal' façade the process of combining library part will be much faster. The ideal façade can then be overlaid with scan data such as orthographic imagery. If the automatic position of window openings does not match the survey data, then the user can simply move points interactively in $3 \mathrm{D}$ or $2 \mathrm{D}$ to fit the survey data as seen in Fig. 6.

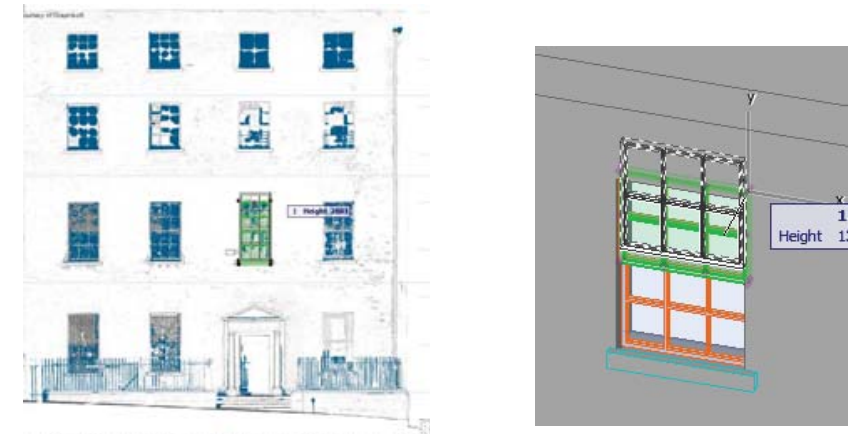

Figure 6. Interactively Modifying Position of Window Openings

\section{B. Integration of HBIM to CityGML}

As discussed in section II there are many advantages for integrating the results of a HBIM model into a 3D GIS. This section outlines the methods currently tested for converting HBIM models to CityGML.

\section{1) Conversion to City GML}

There are a number of different methods available for converting models to CityGML. Because HBIM models are based on the IFC format the model is already classified into semantic classes. This object orientated model makes the conversion into CityGML much easier as the geometry does not have to be classified into objects. The IFC semantic classes simply have to be mapped to the relevant CityGML class.

An initial method for converting models to CityGML was tested using a plug-in for Google SketchUp software which has capabilities for converting SketchUp models into CityGML. Both the Google SketchUp software and the plug in are open source and can be freely downloaded. It also possible to export the HBIM model into in the required format (.skp) for Google SketchUp so there are no interoperability problems between the two software platforms. An advantage of this method is that the geometry is automatically converted to CityGML. However, a disadvantage is that the semantic information from the BIM model is not retained and so it requires the manual association of semantic classes within Google SketchUp. The plug in converts objects into CityGML semantic classes based on layer names. For this reason it is necessary to place elements of the model into appropriate layers and named according to the CityGML semantic class. For example a wall surface that is part of a building should be in a layer named 'Buildng.Wall'. A window which is an opening of a wall should be named 'Buildng.Wall.Window'. Numbers can also be used to accommodate for multiple elements within a model for example 'Buildng1.Wall'.
Once the layers are correctly set up the plug-in can be used to convert the model into a CityGML file. This will then be saved as an xml file and can be opened in any CityGML viewers. Because CityGML is an open standard there are many free viewers available to download, such as the FZK viewer designed at the Karlsruhe Institute of Technology. Next stages of research will be to test other more automated methods of conversion such as using the open source building information model server based on IFC which has export functionality from IFC directly to CityGML.

\section{2) Linking Data}

Once the model has been converted to CityGML the next stage involves adding additional information to the model. This is done by editing the $\mathrm{xml}$ file directly and adding the required attributes. CityGML has a number of predefined attributes for each semantic class. For heritage applications the building attributes for 'year of construction' and 'year of demolition' are very useful for documenting the chronology of a building or building parts. This allows for modeling the changes of a heritage object over time. This is crucial to assist with conservation and restoration of heritage objects. CityGML also allows for external resources to be connected to a model or specific parts of a model as illustrated in Fig. 7. External resources can include databases or websites. This is very beneficial for heritage documentation as it allows for existing heritage records to be linked to the 3D heritage model.

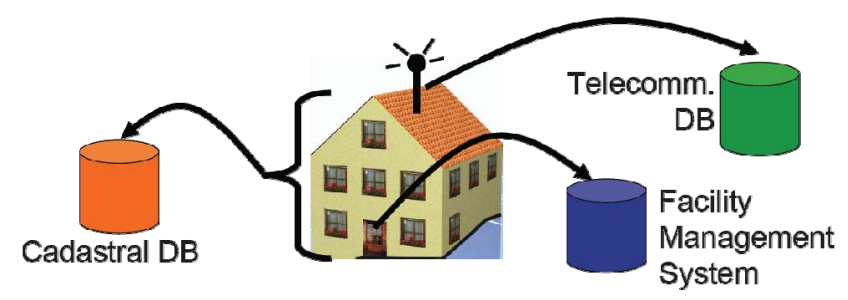

Figure 7. External References attached to parts of a Building [13].

\section{3) New Capabilities}

After converting the model from a BIM model to CityGML the dataset can now be managed an analyzed in a GIS environment. The model is semantically classified into various objects which can all contain attribute information and references to external data sources. This information can contain historical information about the creation, origin and chronology of the heritage object. Further historical documents can be linked to elements in the model for a complete documentation. The model can also be used for tourism applications and easily shared over the web for visualization. Various levels of detail can be defined for objects in the $\mathrm{xml}$ file so that the model can be represented at different detail as required. 


\section{Case Study of Henrietta Street}

A case study has been undertaken to show the application of HBIM and CityGML for modeling and analyzing a heritage site. The heritage site chosen is an $18^{\text {th }}$ century Georgian street located in Dublin, Ireland (Fig.8). The street known as Henrietta Street is one of the earliest Georgian streets in Dublin and is of great historical significance. The street was developed by Luke Gardiner and constructed between 1730 and 1820 . The buildings on Henrietta Street show great classical style architecture and was originally seen city palaces. During the $19^{\text {th }}$ and $20^{\text {th }}$ century's the street fell into disrepair and despite recent restoration work there are still a number of buildings that need urgent attention.

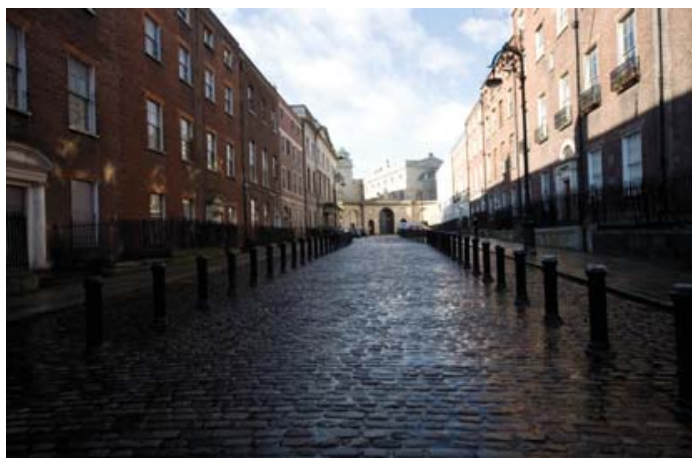

Figure 8. Henrietta Street Dublin

\section{1) Laser Scan Survey}

In order to show how the efficiency of modeling using HBIM the entire street was recorded using laser scanning and image acquisition methods. Eight scans were carried out with $10 \mathrm{~mm}$ resolution using a Trimble GS200 terrestrial laser scanner as seen in Fig. 9. Common targets were surveyed at a higher resolution $(2 \mathrm{~mm})$ in common areas between scans for registration of scans. Five to eight common targets were surveyed to ensure accurate registration results during processing.

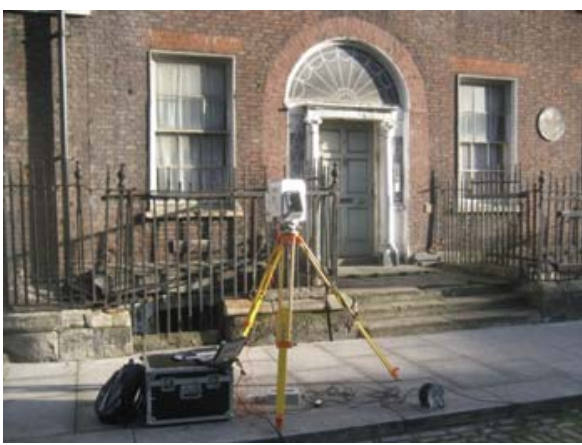

Figure 9. Trimble GS200 Laser Scanner

A number of pre-processing steps were carried out on the scan data before modeling using HBIM. These pre-processing steps included registration, segmentation/filtering, triangulation, texturing, ortho photo creation and the generation of cut sections. All processing of scan data was carried out using Trimble Realworks software. For registration two different methods were used, a cloud based registration and also registration using common points. The results from this can be seen in Table 1. The first three registered scans are shown in Fig. 10. Other pre-processing stages and final point clouds can be seen in Fig. 11.
TABLE I REGISTRATION RESULTS

\begin{tabular}{|r|l|l|l|}
\hline Scan & Resolution & Registration Method & Registration Accuracy \\
\hline 1 & $10 \mathrm{~mm}$ & $\ldots$ & - \\
\hline 2 & $10 \mathrm{~mm}$ & Cloud Mathcing & $7.69 \mathrm{~mm}$ \\
\hline 3 & $10 \mathrm{~mm}$ & Cloud Mathcing & $8.94 \mathrm{~mm}$ \\
\hline 4 & $10 \mathrm{~mm}$ & Common Points & $4.97 \mathrm{~mm}$ \\
\hline 5 & $10 \mathrm{~mm}$ & Common Points & $5.50 \mathrm{~mm}$ \\
\hline 6 & $10 \mathrm{~mm}$ & Common Points & $4.69 \mathrm{~mm}$ \\
\hline 7 & $10 \mathrm{~mm}$ & Common Points & $7.78 \mathrm{~mm}$ \\
\hline 8 & $10 \mathrm{~mm}$ & Common Points & $2.14 \mathrm{~mm}$ \\
\hline
\end{tabular}

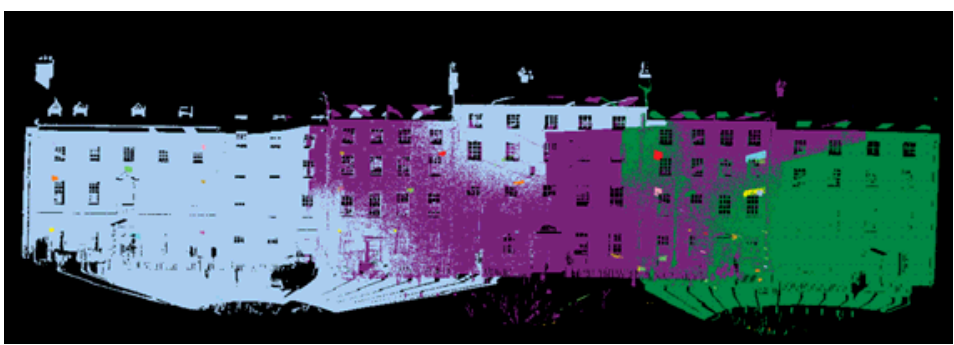

Figure 10. Registration of First Three Scans

The final products from the laser scan and image survey that would be used in the subsequent HBIM stage included segmented point clouds, orthographic imagery (Fig. 12), cut sections, elevations and plans.
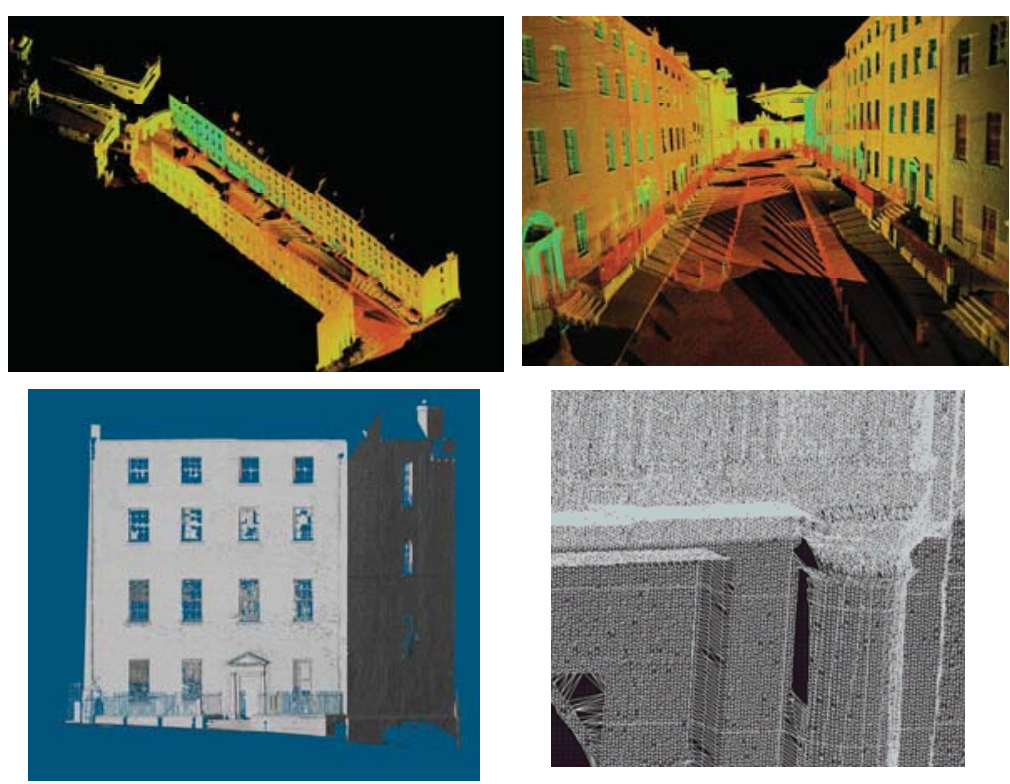

Figure 11. Point Cloud and Mesh Model from Laser Scan Survey.
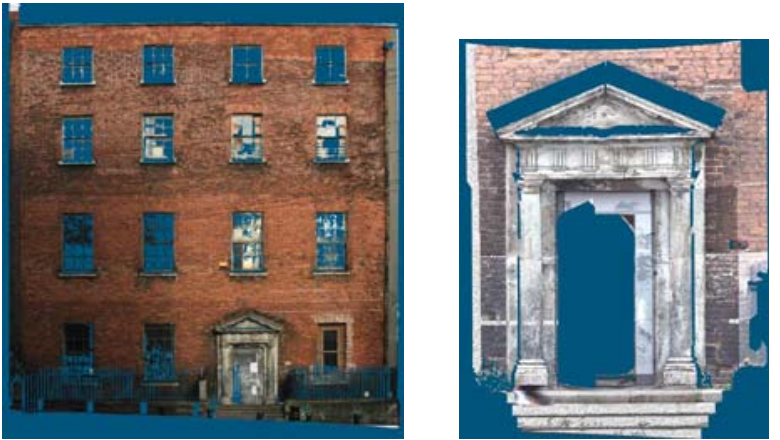

Figure 12. Ortho Imagery from Laser Scan Survey. 


\section{2) Modeling with HBIM}

Next the survey products were imported into the BIM platform ArchiCAD and the HBIM process was applied. 3D Orthographic images were imported in their true position for façade elevations and plans along with ground points and sections. The first stage involved building walls from the plan data (Fig. 13). Next library objects were added for windows, doors, columns and all other building elements. Parameters for library parts were measured from survey data and applied to library part before mapping to survey data.
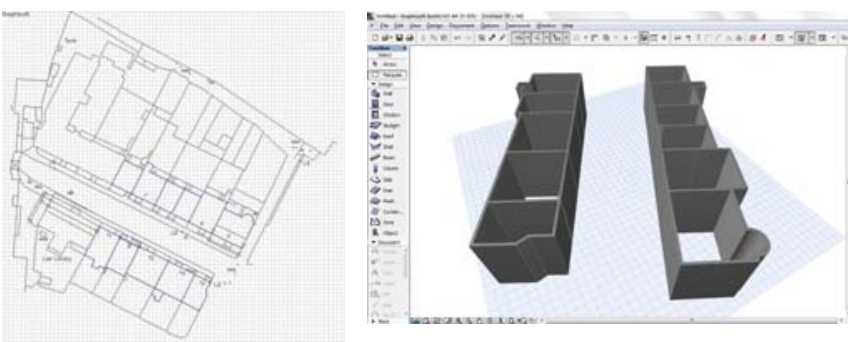

Figure 13. Extruded Walls

Library objects were placed in plan and positioned in elevations and sections (Fig. 14). The model for each building was completed by combining all the required library parts included in the HBIM plug-in. The surrounding road and footpaths were created as mesh models directly from segmented laser scan points. The resulting HBIM model can be seen in Fig. 15. After the model has been created automatic 2D heritage documentation can be created in the form of plans, elevations and sections (Fig. 16).
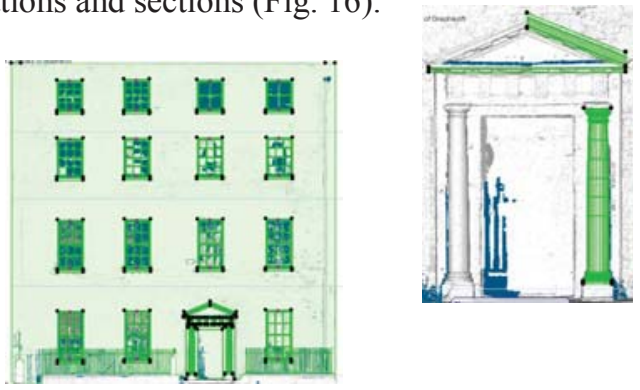

Figure 14. Mapping Parametric Objects to Survey Data.
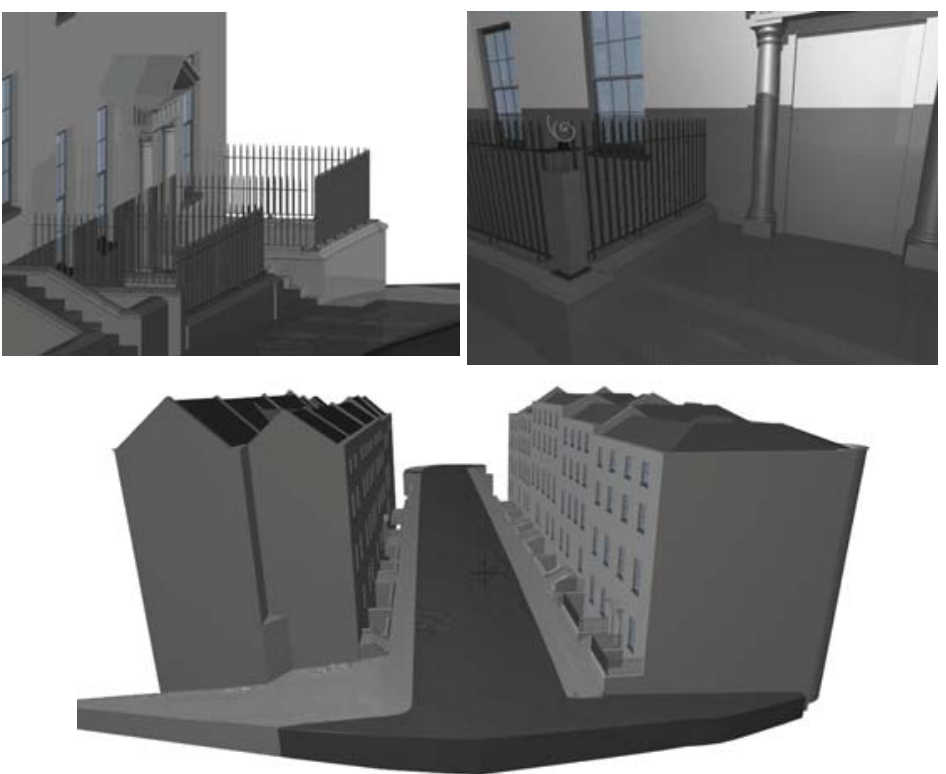

Figure 15. Final HBIM Model
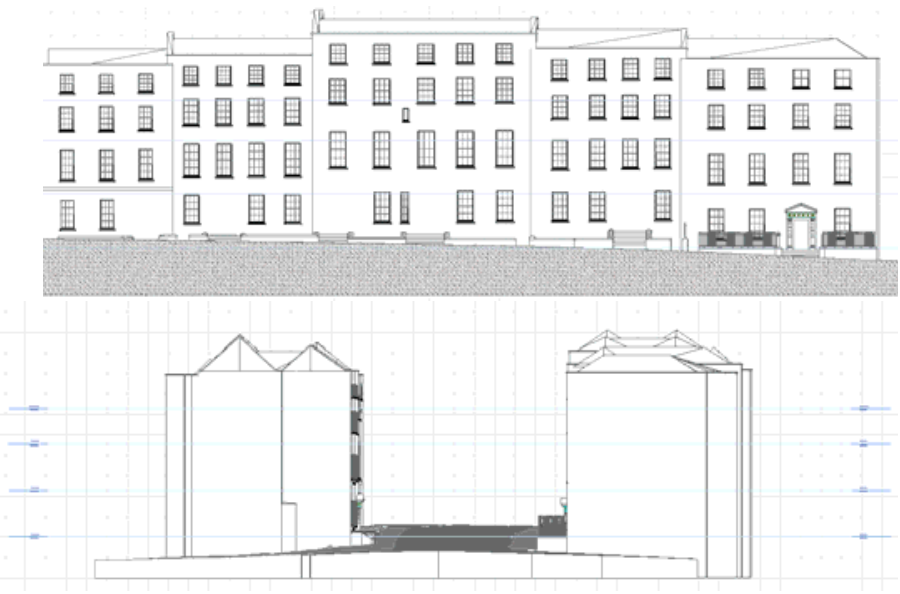

Figure 16. Automated 2D Heritage Documentation

\section{3) Conversion to CityGML}

The final stage of documentation for this case study involved converting the HBIM model for Henrietta Street into CityGML for further GIS analysis. The steps previously described in section 3 were used for this. The HBIM model was imported into Google SketchUp and converted with the CityGML plug-in for SketchUp. This converted geometry and semantic classes as seen in Fig. 17 below. Further attributes were then added to the $\mathrm{xml}$ file. These attributes included function, class, year of construction, description and address for buildings. Attributes for a road class can be seen in Fig. 18 below. The addition of these attributes allows the model to be used as an information system for heritage applications. This model is in an interoperable format that enables sharing of data which is crucial for heritage modeling. This model can be imported into various GIS packages such as ArcGIS to perform further analysis on geometry, semantics, attributes, external references and topology.

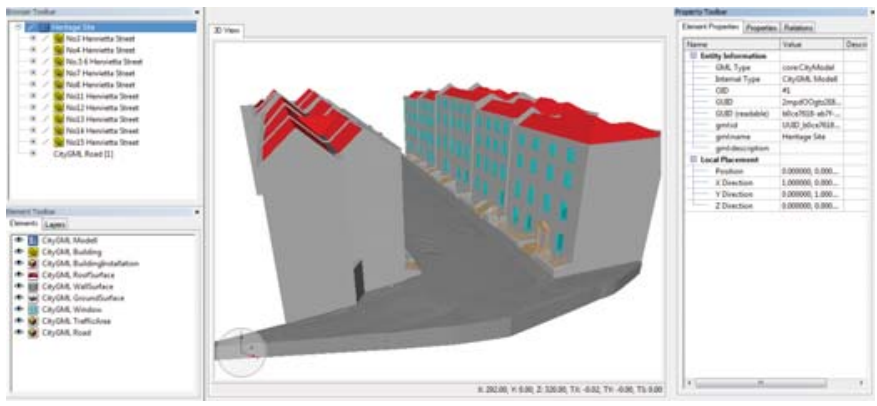

Figure 17. CityGML Model Showing Semantic Classes.

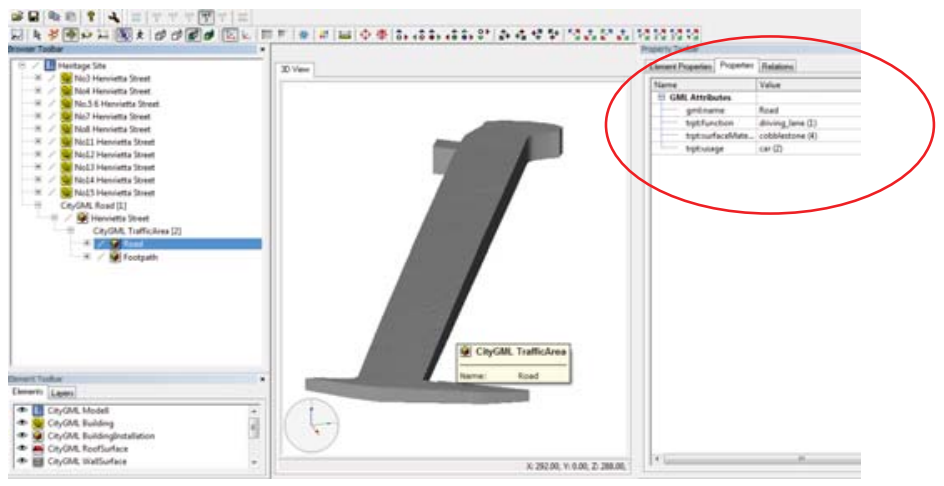

Figure 18. Road Feature Class Showing Associated Attributes. 

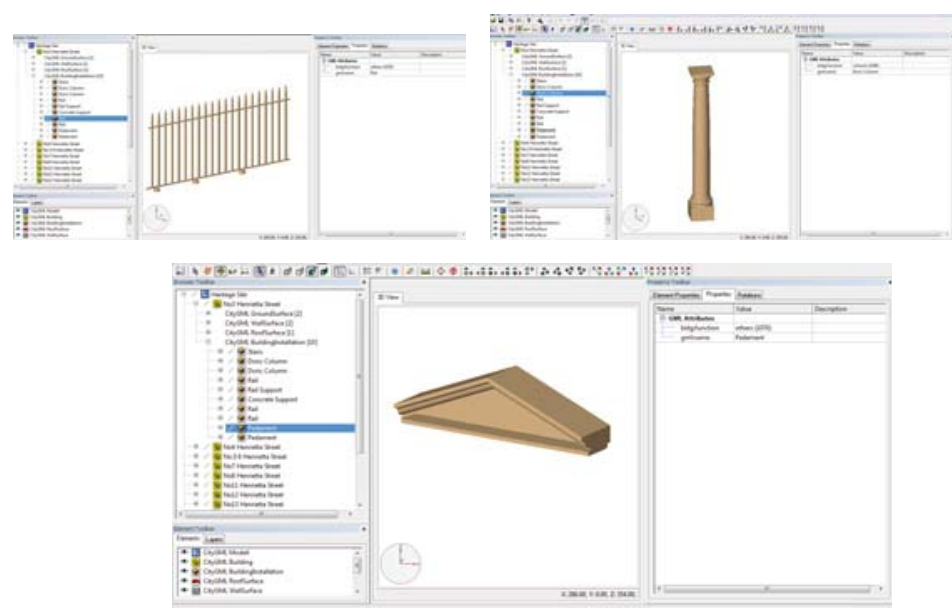

Figure 19. CityGML Objects

\section{NeXT StAGE}

The stages discussed in the previous section outlined the work done to date on these research areas. Some of the next stages of research are discussed in this section.

\section{A. CityGML Extension for HBIM Library Objects}

One of the problems with using CityGML for heritage applications is that the current feature classes and semantics are not detailed enough for describing heritage/architectural detail. For this reason an extension to the CityGML framework will be developed for HBIM objects and relevant necessary attributes. This extension will be implemented as an Application Domain Extension (ADE). This extension will be different to the ADEs previously developed as the proposed ADE will be specific for architectural heritage and will be more detailed than existing ADEs which do not contain the detailed objects that are contained in the HBIM libraries. This ADE will be very beneficial for semantically modeling detailed heritage objects and their attributes that will be interoperable among many software applications.

\section{B. Database Integration}

Another stage of the research will include the development of a database management system for storing, managing and querying CityGML models. As a result of the CityGML structure the data in the xml file can be converted into tables and stored in tables that can be easily queried and served over the web for sharing data. A database management system also facilitates the efficient storage of a large number of heritage models that could be queried. Finally the database could be used to store additional information such as metadata, original survey data such as laser scan point clouds, orthographic imagery and surface models.

\section{CONCLUSION}

The initial results from this research have shown the capabilities for semantic modeling and analysis from the proposed workflow from Laser scan, HBIM to CityGML. The workflow provides new tools and methods for 3D virtual heritage modeling, documentation, management and analysis.
The use of laser scanning and photogrammetry can record very high and accurate levels of detail in the field for heritage documentation. The HBIM process can automate and speed up the modeling stage by using accurate parametric objects that can be altered and mapped to heritage survey data. As a result of HBIM automated conservation documents such as plans, section and elevation can be produced. Finally the integration to CityGML can provide further capabilities for linking the 3D heritage model to information systems. The CityGML model can be integrated into GIS platforms for efficient management and analysis that is required for maintaining important cultural heritage sites.

\section{REFERENCES}

[1] Berlo, Lv \& Laat, Rd 2010, 'Integration of BIM and GIS: The Development of the CityGML GeobBIM Extension', paper presented to 5th International 3D GeoInfo Conference, November 3-4, 2010, Berlin, Germany, Berlin, Germany.

[2] Boehler, W \& Heinz, G 1999, 'Documentation, Surveying, Photogrammetry', paper presented to XVII CIPA Symposium, Olinda, Brazil, 3rd 3 - 3 th October 1999,<http:/cipa.icomos.org/text\%20files/olinda/99c601.pdf>.

[3] Chevrier, C, Charbonneau, N, Grussenmeyer, P \& Perrin, J-P 'Parametric Documenting of Built Heritage: 3D Virtual Reconstruction of Architectural Details', International Journal of Architectural Computing, vol. 08, no. 02, pp. 131-45.

[4] D'Andrea, A 2008, 'Sharing 3D Archaeological Data: Tools and Semantic Approaches', paper presented to 14th International Conference on Virtual Systems and Multimedia, Limassol, Cyprus, October 20th 25 th, 2008.

[5] De Luca, L 2012, 'Methods, Formalisms and Tools for the SemanticBased Surveying and Representation of Architectural Heritage', Applied Geomatics, no. 1866-9298, pp. 1-25.

[6] Delgado, F, Martínez, R, Hurtado, A \& Finat, J 2010, 'Extending functionalities of Management Systems to CityGML', in eWork and eBusiness in Architecture, Engineering and Construction, CRC Press, pp. 409-15.

[7] Fai, S, Graham, K, Duckworth, T, Wood, N \& Attar, R 2011, 'Building Information Modelling and Heritage Documentation', paper presented to XXIII CIPA International Symposium, Prague, Czech Republic, 12th16th September,
Semer. $<$ http://cipa.icomos.org/fileadmin/template/doc/PRAGUE/047.pdf>.

[8] Kolbe, T, Gröger, G \& Plümer , L 2005, 'CityGML - Interoperable Access to 3D City Models', paper presented to International Symposium on Geo-information for Disaster Management, Delft, The Netherlands, 21 - 23 March 2005.

[9] Kolbe, T 2007, 'CityGML Tutorial', Technical University Berlin. $<$ http://www.citygml.org/fileadmin/citygml/docs/CityGML Tutorial Ko lbe_Internet.pdf $>$

[10] McEnroe, GD 2009, 'A Feasibility Study on CityGML for Cadastral Purposes', Eindhoven University Of Technology. $<$ http://alexandria.tue.nl/extra1/afstversl/wsk-i/dsilva2009.pdf >

[11] Murphy M, McGovern E \& Pavia, S 2011, 'Historic Building Information Modelling - Adding Intelligence to Laser and Image Based Surveys', paper presented to 4th ISPRS International Workshop, 3DARCH 2011: "3D Virtual Reconstruction and Visualization of Complex Architectures" Trento, Italy, 2-4 March 2011.

[12] Murphy, M, McGovern, E \& Pavia, S 2009, 'Historic Building Information Modelling (HBIM)', Structural Survey, vol. 27, no. 4, pp. $311-27$.

[13] Open Geospatial Consortium Inc. 2008, OpenGIS® City Geography Markup Language (CityGML) Encoding Standard, Open Geospatial Consortium Inc., Berlin. $<$ http://www.opengeospatial.org >

[14] Ulm, K 2010, 'Virtual 3D City Models - satisfaction through sustainability', Geomatics World, vol. 18, no. 6, pp. 16-8. 